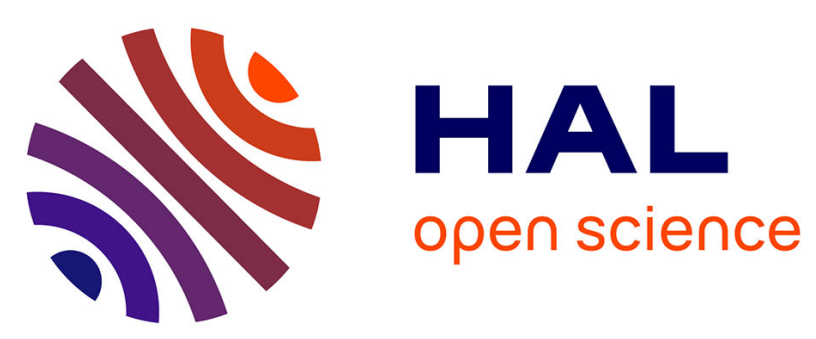

\title{
The partitioning of acetone to different types of ice and snow between 198 and $223 \mathrm{~K}$
}

T. Bartels-Rausch, Christophe Guimbaud, H. Gäggeler, M. Ammann

\section{To cite this version:}

T. Bartels-Rausch, Christophe Guimbaud, H. Gäggeler, M. Ammann. The partitioning of acetone to different types of ice and snow between 198 and 223 K. Geophysical Research Letters, 2004, 31 (16), pp.L16110. 10.1029/2004GL020070 . insu-02068722

\section{HAL Id: insu-02068722 \\ https://hal-insu.archives-ouvertes.fr/insu-02068722}

Submitted on 15 Mar 2019

HAL is a multi-disciplinary open access archive for the deposit and dissemination of scientific research documents, whether they are published or not. The documents may come from teaching and research institutions in France or abroad, or from public or private research centers.
L'archive ouverte pluridisciplinaire HAL, est destinée au dépôt et à la diffusion de documents scientifiques de niveau recherche, publiés ou non, émanant des établissements d'enseignement et de recherche français ou étrangers, des laboratoires publics ou privés. 


\title{
Correction published 3 December 2004
}

\section{The partitioning of acetone to different types of ice and snow between 198 and $223 \mathrm{~K}$}

\author{
T. Bartels-Rausch, ${ }^{1}$ C. Guimbaud, ${ }^{1,2}$ H. W. Gäggeler, ${ }^{1,3}$ and M. Ammann ${ }^{1}$ \\ Received 24 March 2004; revised 11 June 2004; accepted 22 July 2004; published 21 August 2004.
}

[1] The air - ice partitioning of acetone to four different laboratory ice and natural snow samples was investigated at a surface coverage between 0.1 and $6 \%$ and temperatures between 198 and $223 \mathrm{~K}$ using a chromatographic column coupled to an atmospheric pressure chemical ionization mass spectrometer. The adsorption enthalpy and entropy were obtained from the temperature dependence of the measured partitioning coefficient. No significant difference was found among the four ice and snow samples substantially differing in crystallinity and chemical composition. An average adsorption enthalpy of $52 \pm 2 \mathrm{~kJ} / \mathrm{mol}$ and a standard adsorption entropy of $-96 \pm 16 \mathrm{~J} /(\mathrm{mol} \mathrm{K})$ was obtained. A short outlook on partitioning coefficients under atmospheric conditions is given, and the adsorption mechanism is discussed based on the adsorption entropy and enthalpy found. INDEX TERMS: 0320 Atmospheric Composition and Structure: Cloud physics and chemistry; 0365 Atmospheric Composition and Structure: Tropospherecomposition and chemistry; 1863 Hydrology: Snow and ice (1827); 3947 Mineral Physics: Surfaces and interfaces; 4540 Oceanography: Physical: Ice mechanics and air/sea/ice exchange processes. Citation: Bartels-Rausch, T., C. Guimbaud, H. W. Gäggeler, and M. Ammann (2004), The partitioning of acetone to different types of ice and snow between 198 and 223 K, Geophys. Res. Lett., 31, L16110, doi:10.1029/2004GL020070.

\section{Introduction}

[2] Snow and ice have been observed to perturb the acetone concentration of the near-surface polar air [Couch et al., 2000] and suggested to do so in the upper troposphere [Winkler and Trepte, 1998]. Given the significance of acetone as an important radical $\left(\mathrm{HO}_{\mathrm{x}}\right)$ source in the atmosphere [Jaeglé et al., 2001], the partitioning equilibrium between the gas phase and ice needs to be quantified. This equilibrium can be described by the adsorption enthalpy $\left(\Delta \mathrm{H}_{\mathrm{ads}}\right)$ and entropy $\left(\Delta \mathrm{S}_{\mathrm{ads}}\right)$, which determine the partitioning coefficient $\left(\mathrm{k}_{\mathrm{i}}\right)$ under the conditions of interest. Recent studies have reported values of $\Delta \mathrm{H}_{\mathrm{ads}}$ ranging from -46 to $-55 \mathrm{~kJ} \mathrm{~mol}^{-1}$. Even though the combined error bars of the available data overlap, a range of $9 \mathrm{~kJ} \mathrm{~mol}^{-1}$ might induce a significant uncertainty in the values of $\mathrm{k}_{\mathrm{i}} \cdot \Delta \mathrm{S}_{\mathrm{ads}}$ has not been measured so far. In this work, $\Delta \mathrm{H}_{\mathrm{ads}}$ and $\Delta \mathrm{S}_{\mathrm{ads}}$ on ice samples differing in crystallinity and chemical composition

\footnotetext{
${ }^{1}$ Laboratory of Radio- and Environmental Chemistry, Paul Scherrer Institute, Villigen, Switzerland.

${ }^{2}$ Laboratoire de Physique et Chimie de 1'Environnement, CNRS, Orléans, France.

${ }^{3}$ Department for Chemistry and Biochemistry, University of Berne, Bern, Switzerland.
}

Copyright 2004 by the American Geophysical Union. 0094-8276/04/2004GL020070 were determined. Experiments were done at atmospheric pressure and low surface coverage with a chromatographic column coupled to a mass spectrometer. This experiment can be operated also with natural snow samples, and $\mathrm{k}_{\mathrm{i}}$ is the primary observable. Due to the time required to measure the adsorption parameters for one sample, this study cannot address fast processes in snow-packs on the order of weeks or less. Also the processing of a large number of samples under an identical protocol was not possible, which is the reason that this study was performed with four representative samples only.

\section{Experimental Methods}

[3] The experimental set-up has been described in detail by Guimbaud et al. [2003]. Briefly, acetone is dosed to the carrier gas upstream of a chromatographic column, and the arrival of acetone after passage through the column is monitored by feeding the carrier gas directly into the chemical ionization (CI) region of the mass spectrometer, where water cluster ions from a corona discharge act as $\mathrm{CI}$ reagents. The entire flow system up to the CI region was made of PFA Teflon tubing so that faster response times could be achieved than in Guimbaud et al. [2003]. A PFA tube, $8 \mathrm{~mm}$ i.d., packed with different ice or snow samples served as chromatographic column. Polycrystalline ice spheres (PC) were produced by freezing degassed Milli-Q water drops in liquid nitrogen. The spheres were then stored in a closed box at $253 \mathrm{~K}$ for a few months. This annealing leads to recrystallisation and smoothing of the ice surface [Legagneux et al., 2003]. Before packing the column, the ice spheres were sized with calibrated sieves (Retsch, Germany) with a mesh size of $500 \mu \mathrm{m}$ and $710 \mu \mathrm{m}$. Single crystals (SC) were prepared by the group of F. Dominé at LGGE Grenoble, as detailed in Thibert and Dominé [1997]. The SC were chopped in a mil and stored in liquid nitrogen during transport to and at our institute (PSI). The crystals were annealed at $253 \mathrm{~K}$ for 2 weeks and sized with calibrated sieves with a grain size of $500 \mu \mathrm{m}$ and $630 \mu \mathrm{m}$ prior to the experiments. Wind-blown snow was sampled $10 \mathrm{~cm}$ below the snow surface near the high-alpine research station Jungfraujoch (JFJ) $\left(4633^{\prime} \mathrm{N}, 759^{\prime} \mathrm{E}, 3480 \mathrm{~m}\right.$ asl) on February, 14th 2002 ('Snow JFJ'). Temperature was $262 \mathrm{~K}$ and wind speed around $75 \mathrm{~km} \mathrm{~h}^{-1}$. During transport to PSI the snow was kept at $193 \mathrm{~K}$. The sample 'Snow PSI' was taken in the morning of February 6th 2003 nearby PSI. Strong snowfall occurred in the early morning without significant wind at temperatures of around $273 \mathrm{~K}$. Both snow samples were stored at $253 \mathrm{~K}$. To start an experiment, a chromatographic column was packed at $253 \mathrm{~K}$, transported to the laboratory in solid $\mathrm{CO}_{2}$, set into a jacket and finally exposed to the carrier gas stream $\left(\mathrm{N}_{2}, 8 \mathrm{~cm}^{3} \mathrm{~s}^{-1}\right)$. 


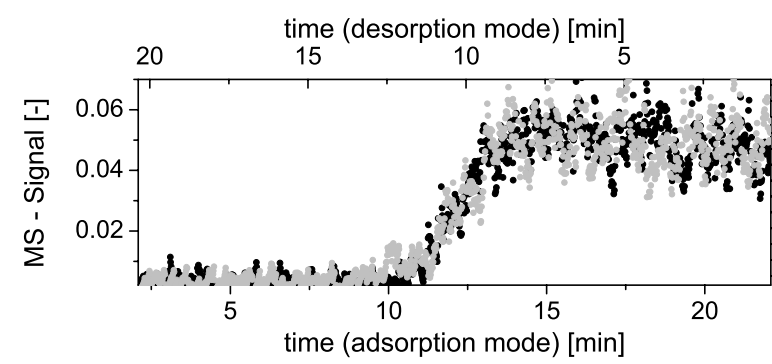

Figure 1. Frontal Chromatogram of polycrystalline ice at $223 \mathrm{~K}$. The plots are centered at their turning point and the desorption curve (grey circles) is plotted against decreasing time to facilitate comparison.

The temperature of the column was controlled by an external cryostat and was varied between $193 \mathrm{~K}$ and $223 \mathrm{~K}$. With the mass spectrometer, we monitored the acetone-proton cluster $\mathrm{H}^{+}\left(\mathrm{CH}_{3} \mathrm{COCH}_{3}\right)$ and water-proton cluster $\mathrm{H}^{+}\left(\mathrm{H}_{2} \mathrm{O}\right)_{3}$. When the water-proton cluster signal reached a stable value, equilibrium of the temperature in the column was assumed and the acetone was turned on to give a concentration of $(2.0 \pm 0.6) \times 10^{11}$ molecules $\mathrm{cm}^{-3}$ (adsorption mode). As soon as the acetone-proton cluster signal reached a stable value, the acetone was turned off, and the decay of the acetone signal was monitored (desorption mode). Monitoring these two proton clusters, rather than the complete cluster spectrum as in Guimbaud et al. [2003] resulted in an improved overall signal to noise ratio.

[4] The surface area available for adsorption was assessed by a BET analysis of methane adsorption isotherms obtained at $77 \mathrm{~K}$ [Legagneux et al., 2002]. The cations sodium, ammonium, potassium, magnesium and calcium, and the anions fluoride, acetate, formate, methane sulfonate, chloride, nitrate, sulfate and oxalate were quantified using ion chromatography after storing and handling the sample [Eichler et al., 2000]. Total insoluble and black carbon in the snow samples was determined using a thermal method [Lavanchy et al., 1999a, 1999b].

\section{Results}

[5] Figure 1 shows a typical breakthrough curve for both the adsorption and desorption modes at $223 \mathrm{~K}$. The retention times $\left(\mathrm{t}_{\mathrm{r}}\right)$, which were defined as turning point of a logistic fit, were $12.1 \mathrm{~min}$ in adsorption and $10.4 \mathrm{~min}$ in desorption mode. The fit aided visualization of this point and has no physical importance. As in this example, retention times in desorption mode were usually $5 \%$ to $15 \%$ shorter than those measured in adsorption mode. No trend in column age or temperature could be seen. For each column, the retention time of acetone was measured at different temperatures over a period of 2 to 5 days. The temperatures were varied at random. Retention times at one temperature turned out to be reproducible during this time period. At low coverage, the partitioning coefficient $\left(\mathrm{k}_{\mathrm{i}}\right)$ can be deduced from the retention time $\left(t_{\mathrm{r}}\right)$ according to equation (1). For a system containing a gas-phase and a surface phase in a given volume, $\mathrm{k}_{\mathrm{i}}$ is defined as the ratio of the number of adsorbed acetone molecules per $\mathrm{cm}^{3}\left(\mathrm{n}_{\mathrm{ads}}\right)$ to their number per $\mathrm{cm}^{3}$ in the gas-phase ( $\mathrm{n}_{\text {gas }}$ ) at equilibrium. $t_{m}$ is the carrier gas hold-up time and $t_{r}^{\text {sys }}$ is the retention time of acetone in the flow system before and after the column. For this set-up, $t_{\mathrm{m}}$ has been found to be $5 \mathrm{~s}$ and $\mathrm{t}_{\mathrm{r}}^{\mathrm{sys}}$ was 46s. The slope and intercept of a van't Hoff plot of $\ln \mathrm{k}_{\mathrm{i}}$ versus $1 / \mathrm{T}$ yield $\Delta \mathrm{H}_{\mathrm{ads}}$ and $\Delta \mathrm{S}_{\mathrm{ads}}^{0}$ (equation (2)). $\Delta \mathrm{G}_{\text {ads }}^{0}$ denotes the standard free energy of adsorption and $\mathrm{K}_{\mathrm{p}}$ the standard adsorption equilibrium constant. In analogy to the standard state for the gas phase $\left(\mathrm{p}^{0}=1 \mathrm{~atm}\right)$, the standard state for the adsorbed species is a surface pressure of $6 \times 10^{-8} \mathrm{~atm} \mathrm{~cm}$ [Kemball and Rideal, 1946], which has also been adopted in other adsorption studies [Donaldson and Anderson, 1999; Sokolov and Abbatt, 2002]. In equation (2) the standard states are expressed as a standard volume, $\mathrm{V}=2.2 \times 10^{4} \mathrm{~cm}^{3}$, and as a standard surface area, $\mathrm{A}=3.7 \times 10^{11} \mathrm{~cm}^{2}$ at $273 \mathrm{~K}$. a/v is the surface to volume ratio under the conditions to which $\mathrm{k}_{\mathrm{i}}$ refers.

$$
\begin{gathered}
k_{i}=\frac{n_{a d s}}{n_{\text {gas }}}=\frac{\left(t_{r}-t_{r}^{s y s}\right)-t_{m}}{t_{m}} \\
\Delta H_{a d s}-T \Delta S_{a d s}^{0}=\Delta G_{a d s}^{0}=R T \ln K_{p}=R T \ln k_{i}-R T \ln \left(\frac{a}{v} \frac{V}{A}\right)
\end{gathered}
$$

Figure 2 shows van't Hoff plots with linear regressions for each snow or ice sample. Data sets for repeated experiments with different columns of the same packing, and experiments in adsorption and desorption mode were merged. A multiple regression and a pair wise partial F-test on the
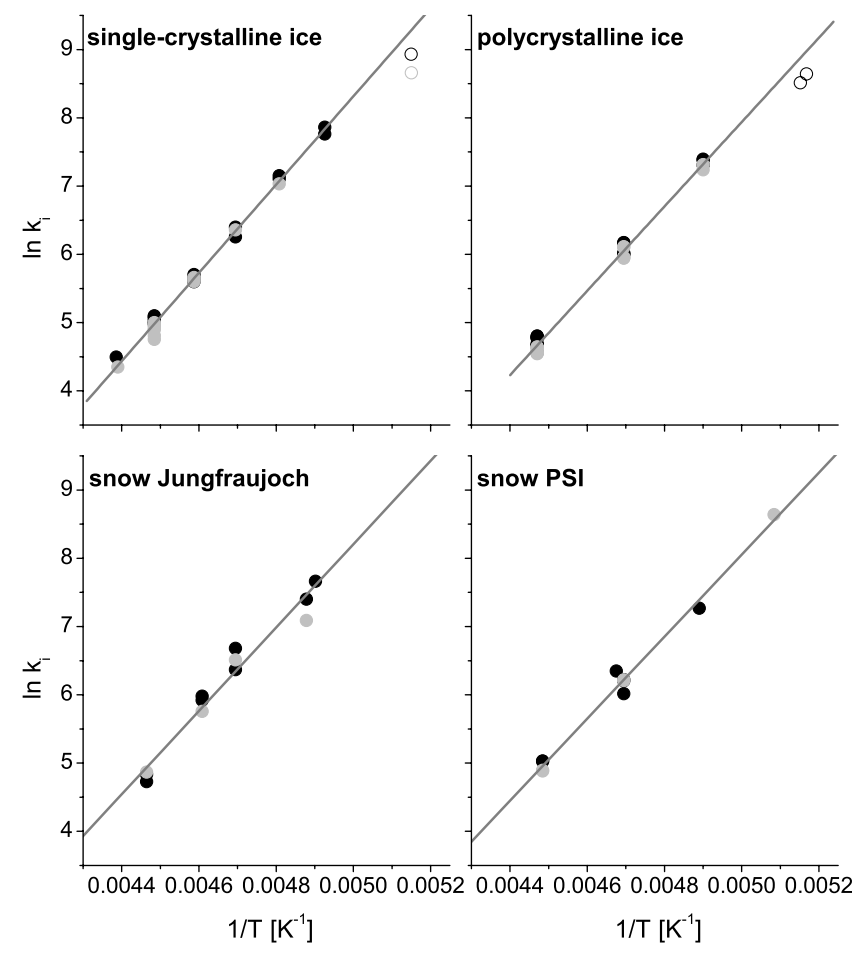

Figure 2. Van't Hoff plots of acetone partitioning coefficient versus inverse temperature. The regression lines are calculated on the merged data sets of adsorption (black circles) and desorption mode (grey circles). Measurements at low temperatures (hollow circles) were not included in the regression, see text for details. 
Table 1. Thermodynamic Parameters of Acetone Adsorption, Surface Coverage $(\theta)$ at Equilibrium, and Chemical Composition of Ice Samples

\begin{tabular}{lcccc}
\hline \multicolumn{1}{c}{ Sample Type } & PC & SC & Snow PSI & Snow JFJ \\
\hline$\Delta \mathrm{H}_{\text {ads }}\left(\mathrm{kJ} \mathrm{mol}^{-1}\right)$ & $-51 \pm 2$ & $-53 \pm 2$ & $-50 \pm 4$ & $-51 \pm 7$ \\
$\Delta \mathrm{S}_{\text {ads }}\left(\mathrm{J} \mathrm{K}^{-1} \mathrm{~mol}^{-1}\right)$ & $-98 \pm 7$ & $-107 \pm 8$ & $-90 \pm 17$ & $-93 \pm 7$ \\
$\theta(\%)$ & $0.2-1.7$ & $0.1-1.7$ & $0.2-6.0$ & $0.2-2.5$ \\
Anions $\left(\mu \mathrm{g} \mathrm{kg}^{-1}\right)$ & 1550 & 1392 & 9881 & 293 \\
Cations $\left(\mu \mathrm{g} \mathrm{kg}^{-1}\right)$ & 2534 & 1311 & 5685 & 196 \\
TC $\left(\mu \mathrm{g} \mathrm{kg}^{-1}\right)$ & - & - & $411 \pm 4$ & $289 \pm 3$ \\
BC $\left(\mu \mathrm{g} \mathrm{kg}^{-1}\right)$ & - & - & $72 \pm 7$ & $18 \pm 2$ \\
BET $\left(\mathrm{cm}^{2} \mathrm{~g}^{-1}\right)$ & 186 & 270 & 244 & 206 \\
\hline
\end{tabular}

slopes and intercepts of each data set showed that the data were statistically identical. The temperature range of the regression was $228 \mathrm{~K}$ to $198 \mathrm{~K}$, excluding the data at $193 \mathrm{~K}$ with significantly shorter retention times at this low temperature and high surface coverage of acetone $(>5 \%)$. No independent variation of coverage and temperature was possible below $190 \mathrm{~K}$ due to technical limitations to further address the low temperature behavior. Table 1 lists $\Delta \mathrm{H}_{\text {ads }}$ and $\Delta \mathrm{S}_{\mathrm{ads}}^{0}$ values obtained.

[6] The surface coverage given in Table 1 was calculated from the product of the residence time $\left(\mathrm{t}_{\mathrm{r}}-\mathrm{t}_{\mathrm{r}}^{\text {sys }}\right)$ and the input flux of acetone, and a maximum surface coverage of $2.7 \times$ $10^{14}$ molecules $\mathrm{cm}^{-2}$ [Winkler et al., 2002]. Results of the BET, cations, anions, total and black carbon measurements are also listed in Table 1. Anions were dominated by chloride, sulfate and nitrate, the cations by potassium, sodium and calcium. The insoluble carbon content seems to derive mostly from organics. The levels fall into the range typically found in snow not affected by local pollution [Lavanchy et al., 1999b]. Formate, acetate, methane sulfonate and oxalate were together $2.5 \%$ of insoluble organic carbon in the Snow JFJ and $4.6 \%$ in the Snow PSI sample.

\section{Discussion}

[7] A goal of this study was to investigate the influence of surface morphology, crystallinity and composition on $\Delta \mathrm{H}_{\text {ads }}$ and $\Delta \mathrm{S}_{\mathrm{ads}}^{0}$. To do so, the results for the different ice and snow samples are plotted in Figure 2 and listed in Table 1. We found no significant difference of $\Delta \mathrm{H}_{\mathrm{ads}}$ and $\Delta \mathrm{S}_{\text {ads }}^{0}$ among the four samples of ice of different origin and thermal history. Note that the identical aging procedure applied to all samples might have led to the similarity in adsorptive properties.

[8] Grains of the Snow PSI and JFJ samples are polycrystalline to a variable extent and may contain minute surface structures [Winkler and Trepte, 1998; Wergin et al., 2002; Legagneux et al., 2003]. The SC consisted of one domain per particle with a random distribution of crystal faces. As Chaix and Dominé [1997] concluded, it appears unlikely that they have a significant degree of surface disorder. In contrast, the rapid freezing of water drops at $90 \mathrm{~K}$ before annealing certainly led to a variable number of crystal domains, grain boundaries, dislocations and grooves in the grains of the PC sample. Even though isothermal metamorphism occurs during annealing, it is likely that a significant degree of polycrystallinity with a network of grain boundaries was retained [Legagneux et al., 2003; Chaix and Dominé, 1997]. On the other hand, as the size of individual ice spheres was comparable in all samples, the similar BET surface areas (see Table 1) suggest that they had similar surface morphologies. BET measurements would respond sensitively to any kind of structure with favorable adsorption properties [Chaix and Dominé, 1997; Legagneux et al., 2003].

[9] On the basis of the few samples considered here, it seems that the crystallinity of aged snow and annealed ice samples does not influence the adsorption properties towards acetone. The absence of significant diffusion into the grain boundary network, which occurs for more soluble species [Huthwelker et al., 2001], is also demonstrated by the symmetry and shape of the breakthrough curves.

[10] The samples used in this study varied considerably in chemical composition (see Table 1). Most of these trace species are located either on the surface or within the grain boundary network [Huthwelker et al., 2001; Baker et al., 2003]. Especially ionic species tend to increase the degree of disorder and the thickness of the disordered layer on the surface [Suzanne et al., 2003]. If we assume that all contaminants detected in our analysis are located at the surface, a significant density would result in the surface layer, especially for the Snow PSI sample. However, the contaminated ice samples seem to expose similar bonding options or number of available water molecules to acetone as pure ice.

[11] The standard adsorption entropy of acetone on ice has not been discussed previously. The standard adsorption entropy of acetone on water of $-94 \pm 8 \mathrm{~J}(\mathrm{~mol} \mathrm{~K})^{-1}$ [Donaldson and Anderson, 1999] is very close to that on ice of $-96 \pm 16 \mathrm{~J}(\mathrm{~mol} \mathrm{~K})^{-1}$ obtained in this study. This might indicate an identical number of degrees of freedom for adsorbed acetone on both phases. Comparison of $\Delta \mathrm{S}_{\text {ads }}^{0}$ of acetone with that of a few other organic compounds indicates that for a given functionality, $\Delta \mathrm{S}_{\text {ads }}^{0}$ tends to increase with the organic chain length [Sokolov and Abbatt, 2002].

[12] The adsorption enthalpy of acetone was independent of the type of ice, and an average value of $-52 \pm 2 \mathrm{~kJ} \mathrm{~mol}^{-1}$ can be given. This value is very close to $\Delta \mathrm{H}_{\text {ads }}$ of acetone on water of $-50 \pm 2 \mathrm{~kJ} \mathrm{~mol}^{-1}$ [Donaldson and Anderson, 1999], indicating that in both processes a similar number of hydrogen bonds are formed. The enthalpy of adsorption was, on both phases, found to be more negative than the enthalpy of solvation $\left(\Delta \mathrm{H}_{\mathrm{solv}}=-40 \mathrm{~kJ} \mathrm{~mol}^{-1}\right)$ and the enthalpy of condensation $\left(\Delta \mathrm{H}_{\mathrm{cond}}=-31 \mathrm{~kJ} \mathrm{~mol}^{-1}\right)$. Obviously the acetone water interaction $\left(\Delta \mathrm{H}_{\mathrm{ads}}\right.$ and $\left.\Delta \mathrm{H}_{\text {solv }}\right)$ is stronger than the acetone - acetone interaction $\left(\Delta \mathrm{H}_{\text {cond }}\right)$. The lower overall energy gain for solvation than for adsorption indicates that during adsorption the acetone molecule is not completely buried in the bulk ice phase, as this step requires an energyconsuming restructuring of the water phase.

[13] Several other groups have also studied the adsorption enthalpy of acetone on ice at temperatures typical for the upper troposphere and at low surface coverage. Dominé and Rey-Hanot [2002]: $-55 \pm 7 \mathrm{~kJ} \mathrm{~mol}^{-1}(0.03 \%<\theta<7 \%$; $193 \mathrm{~K}<\mathrm{T}<213 \mathrm{~K})$; this work: $-52 \pm 2 \mathrm{~kJ} \mathrm{~mol}^{-1}(0.1 \%<$ $\theta<6 \% ; 193 \mathrm{~K}<\mathrm{T}<223 \mathrm{~K})$; Winkler et al. [2002]: $-46 \pm$ $7 \mathrm{~kJ} \mathrm{~mol}^{-1}(0.003 \%<\theta<4 \% ; 198 \mathrm{~K}<\mathrm{T}<218 \mathrm{~K})$; Guimbaud et al. [2003]: $-55 \pm 6 \mathrm{~kJ} \mathrm{~mol}^{-1}(0.01 \%<\theta<$ $3 \% ; 203 \mathrm{~K}<\mathrm{T}<243 \mathrm{~K})$. While these studies differ in experimental approach, they all derive the number of adsorbed acetone molecules from the loss of gas-phase molecules integrated until equilibrium is established. Note 
Table 2. Free Energy of Adsorption $\left(\Delta \mathrm{G}_{\text {ads }}^{0}\right)$ and Partitioning Coefficient $\left(\mathrm{k}_{\mathrm{i}}\right)$ of Acetone to Ice for Cirrus Clouds and Snow-Pack at Temperatures $(\mathrm{T})$ characteristic of the Arctic (A)

\begin{tabular}{lcccc}
\hline & $\mathrm{T}(\mathrm{K})$ & $\mathrm{a} / \mathrm{v}\left(\mathrm{cm}^{2} / \mathrm{cm}^{3}\right)$ & $\Delta \mathrm{G}_{\mathrm{ads}}^{0}(\mathrm{~kJ} / \mathrm{mol})$ & $\mathrm{k}_{\mathrm{i}}(-)$ \\
\hline Contrails & $213^{\mathrm{a}}$ & $1 \times 10^{-4 \mathrm{a}}$ & -31.6 & $3 \times 10^{-4}$ \\
Cirrus & $213^{\mathrm{a}}$ & $3 \times 10^{-5 \mathrm{a}}$ & -31.6 & $1 \times 10^{-4}$ \\
Snow pack (A) & 247 & $20^{\mathrm{b}}$ & -28.4 & 2 \\
\hline
\end{tabular}

${ }^{\mathrm{a}}$ Schröder et al. [2000].

${ }^{\mathrm{b}}$ Dominé et al. [2001].

that $\mathrm{k}_{\mathrm{i}}$ in this study is also directly linked to $\mathrm{n}_{\mathrm{ads}}$. We also observed that the scatter in the data was significantly larger at higher temperatures above $230 \mathrm{~K}$ (not shown), in part due to technical limitations (low retention times). This might explain the discrepancy to the adsorption enthalpy value reported by Guimbaud et al. [2003] using the same method and including data up to $243 \mathrm{~K}$.

[14] The four samples of this study mark the extremes of variations in surface defects, grain boundary density and chemical composition as they occur in annealed ice ranging from single crystal to polycrystalline ice and to natural snow. This range should also include the structural features of the samples used in the other studies cited, which were all prepared by freezing a liquid water film based on a very similar protocol.

[15] The partitioning of acetone to ice under relevant situations can now be estimated by calculating $\Delta \mathrm{G}_{\text {ads }}^{0}$ and $\mathrm{K}_{\mathrm{p}}$ from $\Delta \mathrm{H}_{\mathrm{ads}}, \Delta \mathrm{S}_{\mathrm{ads}}^{0}$ and the temperature of interest (equation (2)). Then, $\mathrm{k}_{\mathrm{i}}$ is obtained from $\mathrm{K}_{\mathrm{p}}$ with equation (3) using the relevant surface to volume ratio $(\mathrm{a} / \mathrm{v})$ and the standard state $(\mathrm{A} / \mathrm{V})$.

$$
k_{i}=K_{p} \cdot \frac{a}{v} \cdot \frac{V}{A}
$$

A few examples are given in Table 2, which indicate that the partitioning of acetone to ice and snow surfaces is too small to significantly impact the gas-phase concentration of acetone on a larger scale in cirrus clouds or contrails. But the expected temperature dependence of the partitioning coefficient, which may describe emission of acetone from the snow pack at high temperatures and adsorptive uptake at low temperature, might be helpful to identify key processes leading to the observed acetone gas-phase concentration on a local scale and its diel cycle at Alert [Grannas et al., 2002].

[16] Acknowledgments. This work was part of a project by the European Commission (CUT-ICE: EVK2-CT1999-00005) and was funded by the Swiss Federal Office for Education and Science (99.00491-2). We thank Mr. Staub and A. Vlasenko for help on sampling snow at the Jungfraujoch, F. Dominé for providing single ice crystals, F. Dominé and L. Legagneux for help and instructions on the BET method, S. Szidat for $\mathrm{TC}$ and $\mathrm{BC}$ measurements and $\mathrm{S}$. Brütsch for the IC measurements.

\section{References}

Baker, I., D. Cullen, and D. Iliescu (2003), The microstructural location of impurities on ice, Can. J. Phys., 81, 1-9.
Chaix, L., and F. Dominé (1997), Effect of the thermal history of ice crushed at $77 \mathrm{~K}$ on its surface structure as determined by adsorption of $\mathrm{CH}_{4}$ at low surface coverage, J. Phys. Chem. B, 101(32), 6105-6108.

Couch, T. L., A. L. Sumner, T. M. Dassau, P. B. Shepson, and R. E. Honrath (2000), An investigation of the interaction of carbonyl compounds with the snowpack, Geophys. Res. Lett., 27(15), 2241-2244.

Dominé, F., and L. Rey-Hanot (2002), Adsorption isotherms of acetone on ice between 193 and 213 K, Geophys. Res. Lett., 29(18), 1873, doi:10.1029/2002GL015078.

Dominé, F., A. Cabanes, A. S. Taillandier, and L. Legagneux (2001), Specific surface area of snow samples determined by $\mathrm{CH}_{4}$ adsorption at $77 \mathrm{~K}$ and estimated by optical microscopy and scanning electron microscopy, Environ. Sci. Technol., 35(4), 771-780.

Donaldson, D. J., and D. Anderson (1999), Adsorption of atmospheric gases at the air-water interface: 2 . C-1-C-4 alcohols, acids, and acetone, J. Phys. Chem. A, 103(7), 871-876.

Eichler, A., M. Schwikowski, H. W. Gäggeler et al. (2000), Glaciochemical dating of an ice core from upper Grenzgletscher (4200 m asl), J. Glaciol., 46, 507-515.

Grannas, A. M., et al. (2002), A study of photochemical and physical processes affecting carbonyl compounds in the Arctic atmospheric boundary layer, Atmos. Environ., 36(15-16), 2733-2742.

Guimbaud, C., T. Bartels-Rausch, and M. Ammann (2003), An atmospheric pressure chemical ionization mass spectrometer (APCI-MS) combined with a chromatographic technique to measure the adsorption enthalpy of acetone on ice, Int. J. Mass Spectrom., 226, 279-290.

Huthwelker, T., D. Lamb, M. Baker et al. (2001), Uptake of $\mathrm{SO}_{2}$ by polycrystalline water ice, J. Colloid Interface Sci., 238(1), 159-174.

Jaeglé, L., D. J. Jacob, W. H. Brune, and P. O. Wennberg (2001), Chemistry of $\mathrm{HO}_{\mathrm{x}}$ radicals in the upper troposphere, Atmos. Environ., 35(3), 469489

Kemball, C., and E. K. Rideal (1946), The adsorption of vapours on mercury: 1. Non-polar substances, Proc. R. Soc. London, Ser. A, 187, 53-73.

Lavanchy, V. M. H., H. W. Gäggeler, S. Nyeki, and U. Baltensperger (1999a), Elemental carbon (EC) and black carbon (BC) measurements with a thermal method and an aethalometer at the high-alpine research station Jungfraujoch, Atmos. Environ., 33, 2759-2769.

Lavanchy, V. M. H., H. W. Gäggeler, U. Schotterer et al. (1999b), Historical record of carbonaceous particle concentrations from a European high-alpine glacier (Colle Gnifetti, Switzerland), J. Geophys. Res., 104(D17), 21,227-21,236.

Legagneux, L., A. Cabanes, and F. Dominé (2002), Measurement of the specific surface area of 176 snow samples using methane adsorption at 77 K, J. Geophys. Res., 107(D17), 4335, doi:10.1029/2001JD001016.

Legagneux, L., T. Lauzier, F. Dominé et al. (2003), Rate of decay of specific surface area of snow during isothermal experiments and morphological changes studied by scanning electron microscopy, Can. J. Phys., $81,459-468$.

Schröder, F., B. Kärcher, C. Duroure et al. (2000), On the transition of contrails into cirrus clouds, J. Atmos. Sci., 57, 464-480.

Sokolov, O., and J. P. D. Abbatt (2002), Adsorption to ice of n-alcohols (ethanol to 1-hexanol), acetic acid, and hexanal, J. Phys. Chem. A, 106(5), $775-782$.

Suzanne, J., D. Ferry, B. Demirdjian et al. (2003), The effect of $\mathrm{HCl}$ adsorption on the structure and dynamics of the ice surface, Can. J. Phys., $81,415-422$

Thibert, E., and F. Dominé (1997), Thermodynamics and kinetics of the solid solution of $\mathrm{HCl}$ in ice, J. Phys. Chem. B, 101(18), 3554-3565.

Wergin, W. P., A. Rango, J. Foster et al. (2002), Irregular snow crystals: Structural features as revealed by low temperature scanning electron microscopy, Scanning, 24, 247-256.

Winkler, D. M., and C. E. Trepte (1998), Laminar cirrus observed near the tropical tropopause by LITE, Geophys. Res. Lett., 25(17), 3351-3354.

Winkler, A. K., N. S. Holmes, and J. N. Crowley (2002), Interaction of methanol, acetone, and formaldehyde with ice surfaces between 198 and 223 K, Phys. Chem. Chem. Phys., 4(21), 5270-5275.

M. Ammann, T. Bartels-Rausch, H. W. Gäggeler, and C. Guimbaud, Laboratory of Radio- and Environmental Chemistry, Paul Scherrer Institute, CH-5232 Villigen, Switzerland. (markus.ammann@psi.ch) 